\title{
Publish or Perish! Sharing Best practices for a Writing Instructor Led "Writing for Publication" Course
}

\author{
Sarbani Sen Vengadasalam (Corresponding author) \\ Writing Program, Department of English, Rutgers University, USA \\ Email: sarbani@english.rutgers.edu \\ ORCID: https://orcid.org/0000-0002-9344-0018
}

Received: $11 / 04 / 2020$

Accepted: 02/06/2020

Published: 01/07/2020

Volume: 1 Issue: 2

How to cite this paper: Vengadasalam, S.S. (2020). Publish or Perish!: Sharing Best practices for a Writing Instructor Led "Writing for Publications" Course. Journal of Critical Studies in Language and Literature, 1(2), 1-9

DOI: https://doi.org/10.46809/jcsll.v1i2.13

Copyright (C) 2020 by author(s) and Global Talent Academy Ltd. This work is licensed under the Creative Commons Attribution International License (CC BY 4.0).

http://creativecommons.org/licenses/by/4.0/

\section{(c) (i)}

\begin{abstract}
There is an urgent need to teach "Writing for Publications" classes to graduate and doctoral students. Though the debate about who should instruct such classes continues, the paper proffers best practices for writing instructors to use while teaching it. The paper highlights the need for scholar-participants to opt for modeling as a way to familiarize themselves with disciplinary and journal conventions. The paper expands on the way online peer review workshops could be conducted at milestone points in the semester to elevate and formalize peer reviews, so integral to the publication process. A sample syllabus with week-by-week activity break-up is offered.
\end{abstract}

Keywords: Writing for Publication, Publish or Perish, Modeling, Online Peer Review

\section{Introduction}

While universities are hotbeds of path-breaking innovation and ground-breaking discoveries, many stories of individual student experimentation and achievement remain untold. This is because student researchers are not coached in writing about their research as well as they are guided in carrying them out. Since Professors in other academic disciplines may not be willing to step into the writing instructor's shoes, it may be expedient if the writing teacher measures up in the attempt to offer instruction to interdisciplinary scholars to write for publication. The question is often raised: how can a writing teacher who is trained in a specific way of writing for journals cater to those from S.T.E.M. (Science, Technology, Engineering, Math) disciplines that form a majority of the student population, follow the I.M.R.A.D. (Introduction-methodology-resultsanalysis and discussion) format, and often need the most guidance in writing their papers since their expertise lies in scientific research than argumentative persuasion? This paper takes the perspective that writing instructors can successfully steer "Writing for Publication" courses and offers practitioner insights and best practices for writing teachers to conduct the class as an interdisciplinary course for all graduate and doctoral students. 


\section{Interdisciplinarity as an Instructional Strategy}

Even if the students come from different research areas, it may be practical for universities to ask writing teachers to teach the Writing for Publication classes since the purpose of the class is to teach participants how to write about their research for a journal audience. However, this does not imply that teachers trained to teach writing hold classes at various departments, one department at a time. That Writing for Publications assumes and embraces an interdisciplinary approach is a wholesome best practice for students and the instructor since, as Woods (2007) rightly points out, "it is in the process of negotiating meaning across disciplines that the rewards lie..." (853). Even if this area of negotiation is under-theorized in academic discourse, it is an incontrovertible fact that interdisciplinary skills characterize the workplace of today. When interdisciplinary learning is accepted as a primary principle of the curriculum design, it denotes that the syllabi will incorporate interdisciplinary activities and texts that offer learners opportunities to, as Ivanitskaya et al (2002) term it, “ to develop critical thinking and meta-cognitive skills through an understanding of the relations derived from different disciplines"(95). Taking the idea forward, Woods (2007) elaborates that "developing such interdisciplinary know-how is a worthwhile adjunct to disciplinary expertise and its development has a legitimate place in university curricula. If the intention is to enable students to engage in effective interdisciplinary communication in their future lives, it could be argued that developing the ability in dealing with the complex negotiation of meaning and understanding should be one of the principal aims of interdisciplinary learning at the university" (856). Even though they may be doing it at an advanced level and in a research university setup, Writing for Publications courses contribute consciously to this interdisciplinary interchange in the same way that Writing Across the Curriculum courses do at the undergraduate level.

Our workplaces are becoming interdisciplinary where members have to work harmoniously and knowledgeably with coworkers from different disciplines and areas of expertise. When Writing for Publications operates in an interdisciplinary environment, students learn from each other about current research trends and discoveries in other disciplines. This not only generates interesting academic conversations in the classroom but also give student writers the insights into how a certain academic event or discovery-such as the discovery of reverse analysis-influences different disciplines and impacts research strategies.

When the course description clarifies that the adopted approach is interdisciplinary, students come in with the knowledge that their work will be read and critiqued by interdisciplinary peers (which includes the instructor) who will be giving them immediate feedback on their communication competence. Since interdisciplinarity is the framework for all collaboration, the dialogs about writing generated between the teacher and the student are as important to the researchers' growth as a writer as the moments that arise between writer and peer reviewers. In addition to the greater interchanges of ideas, the interdisciplinary environment leads to a significant improvement in the clarity and reader-friendliness of the student's writing. Since the writers know that their writing has to make sense to scholars from other disciplines; they avoid jargon, put down all assumptions, and clarify inferences. As reader consciousness is central to the progress of any writer, this is a valuable outcome from the course.

Another principle that a Writing for Publications course pedagogy may want to embrace is the use of online peer review workshops. Since peer review is a time-consuming process but a necessary exercise in developing critical reading, questioning, and commenting skills that all graduate students in general, and Writing for Publications students in particular, need to master, peer review workshops must be carefully planned but held online. Careful planning involves creating and having reviewers fill out review forms that posit questions that are at the cognitive level of evaluation. These forms will not only offer a review summary but also aid students in composing helpful reader response notes. Put differently, the peer review questionnaires can be so devised that they help the reviewers develop opinions that they justify in their response pieces. As for the reader response notes, they need to be organized in S.W.S. (strengths-weaknesses-suggestions) format as is common practice in the scholarly publication community. While composing their reader response notes, students develop their review skills as well as their writing proficiencies. Using S.W.S. as a suggested guideline ensures that the review essays are structured, comprehensive, and balanced since highlighting strengths or what was done right is as important to the growth of both the writer and the reviewer as the spelling out of weaknesses and the offering of suggestions or how some areas could be improved. While separate peer reviews for content and mechanics need to be planned, peer review forms can be so designed that they double up as self-review checklists that students fill out and attach while submitting their work. Even though peer reviewers may be able to spot inadvertent plagiarism, students must be asked to submit their work through automated plagiarism checkers. After all, research is as much about integrity as it is about innovation and scholarship.

Holding online peer review workshops at crucial points in the paper's development has advantages that go way beyond convenience and savings on paper and class time. The online workshops help the writers realize the extent and significance of the role of the physically absent peer reviewer in the process of journal publication. The peer reviewer is not only standing in for the reader until the article is published but s/he is also articulating important ideas about the structure, presentation, and the writing mechanics of the paper in the feedback notes. The peer review questionnaires cam be also so devised that they help the reviewers develop opinions that they can enunciate and justify in their response pieces. While the peer response essay is an important way to develop critical and evaluative skills in students as readers and writers, they are also the conduits through which interdisciplinary inputs are communicated to the writers in the form of suggestions. Through the reader responses they get, student writers get a clear idea if s/he is being understood and if what is being understood is what $\mathrm{s}$ /he had wanted to be communicated. While composing his or her reader response paragraphs, the peer reviewer stands to 
gain as much as the writer. Not only does the peer reviewer get to practice writing and critical thinking skills, but s/he also develops a deep awareness of the audience. S/he was the audience of the paper s/he just analyzed, and now s/he gets to wear a different hat as the SWS writer whose audience is the author of the reviewed paper s/he just read. In learning how to both provide and act on the peer reviews they received, course participants grow to realize that writing is a recursive and collaborative rather than a solitary process. In learning how to both provide and act on the peer reviews they receive, course participants grow to realize that writing is a recursive and collaborative rather than a solitary process.

At this juncture, it may be worthwhile to discuss what this pedagogical shift to online would imply in terms of learning outcomes. It is both undeniable and understandable that peer reviewers' behaviors and comments change when conducting review online for three reasons: they had more time to reflect before posting comments, which are now there for good, and for all to see. As Hassanal and Sashittal (2017) point out, when online, "students do exercise a great deal of care in terms of what they say and do while working with others. The higher levels of care trigger both impression management behaviors and perceptions that others are contributing more. The perceptions that others are contributing more seem instrumental in shaping students' decisions to contribute more themselves" (219). It is perhaps for this reason that Breuch (2004) went so far as to claim that virtual peer review is "remediation of face-to-face peer review," pointing out that both the writer and the peer reviewer exhibit a greater sense of audience consciousness when peer reviews are conducted online (8).

Student-writers apart, the system of holding online peer review workshops holds many advantages for the teachers too. The practice of doing peer review online implies that instructors have a digital record that they can use to monitor the efficacy of the workshop tools such as the peer review forms. Additionally, it gives the teacher the ability to facilitate multiple reviews in the classroom. Multiple peer reviews and group reviews offer students a greater exposure to ideas and range of perspectives on their writing that is so important to the students' growth as a writer. The option to have multiple reviewers is a benefit that is especially critical to the success of Writing for Publications students since they have to learn both to receive and offer feedback in order to succeed in their publishing careers. The providing of meaningful interfaces for interaction with peers in these workshops thus become the offering of what Liu et al (2002) term as a foundation for students to evaluate a peer's work in a professional setting as it makes them realize that reviewing a peer's product is a professional obligation and aid to advancement (824). Also, these interfaces improve the outcome of the class because, as Papadopoulos et al (2017) correctly point out, "students who provide reviews to their peers ('assessors" or 'givers') reach higher levels of learning gains in comparison to students who typically only receive peer reviews ('assesses' or 'receivers')" (71).

Interdisciplinary online peer review workshops are good exercises to stimulate conversation about how research has been presented. Liu et al (2002) describe how Michigan State University (M.S.U) students who, having gone through an interdisciplinary peer workshop declared that because of it, they "learned how to explain jargon terminology, learned about structures of the review process, and learned about thinking from other fields." They saw the strengths and the weaknesses of their own papers such as "forced idea synthesis" or "holes and deficiencies" and got "perspectives on our own progress and quality of results" (827). Even if peer reviewers from other disciplines could not comment on the validity of specific methods or results or similar research nuances — only the students' $\mathrm{PhD}$ supervisors can do that - the vast majority of students in the M.S.U. study thought that "people outside your discipline clear up jargon and make it more understandable," and even if they were "non-experts" from different fields, the benefits of such peer reviews far outweigh the time invested (Ibid). Though more explicit connections to peer review theory and practice are clearly necessary to further explore the ramifications of virtual group peer reviews, it is true that "even writers who decide not to follow a peer's advice" may actually learn as much as a writer who follows the advice because it gives all students, as Jensen (2016) interestingly put it, "an opportunity to think their idea through." Importantly, online peer review workshops give all students "the gift of having some responsibility - some authority for their own learning, empowering them as both readers and writers" (2). Their growth and evolution are, therefore, similar to what Nava-Whitehead et al (2011) describe as the movement by "the novice from the periphery of a community to its center, as he or she becomes more active and engaged within the culture and eventually assumes the role of an expert..." (361). Since many of the enrolled students seemed to dread writing, Pritchard \& Morrow (2017) began to hold online peer workshops as a way to overcome that roadblock, develop empathy, and "positive attitudes about writing, increased motivation to revise, increased quantity of writing,..." (8).

\section{The Modelling Approach}

While the value and possibilities of interdisciplinarity cannot be overemphasized, interdisciplinary awareness cannot be developed at the expense of disciplinary expertise. In a course as challenging as Writing for Publications, students need to receive intensive training in mastering disciplinary requirements and journal specifications. Every publication project, hence every Writing for Publications course, needs to begin with a proposal. In the world of journal writing where approximately about one-fifth of the articles submitted are accepted, the writer who evinces a good understanding of the requirements of the target journal earns a response. While in-class guidance and helpful resources may be required in a class to bolster the students' ability to in market their paper to the editors of their preferred publications, what is perhaps most critical is that we find a way to help prospective writers develop an enhanced awareness of disciplinary conventions and audience expectations. Offering modeling exercises where the researcher is asked to use one or two exemplary articles from the targeted publication to evolve a guide for his or her own writing could help students develop expertise and familiarity with disciplinary and writing conventions. In my own Writing for Publications class at Rutgers University, I used two such scholarly article 
modeling assignments or S.A.M.1 \& 2. If S.A.M.1 concentrates on the macro structure, S.A.M.2 focuses on the microstructure. While in S.A.M.1, I have students review and take notes on topic sentences, sectional headings, theses, titles, and flow of one section into another; they examined and record their observations on the academic phraseology, length of the section, and relationship of one sentence to another in a paragraph as well as use of verb-tenses, noun-pronoun and activepassive voice in SAM 2. Through their close reading and note taking from the model articles, students began to work out their unique ways to present their research or their Macro outline with micro details. They used S.A.M.1 \& 2 to work out their scientific or scholarly article plan in a way that is unique to them and also demonstrates their awareness of disciplinary specifications and target journal's requirements. These patterning exercises can be empowering for the writing instructors in reaching out to their interdisciplinary students as well, proving the validity of Ackerman and Perkins argument (1989) that "interdisciplinary learning augments instead of threatening traditional teaching styles" (79).

As modeling and planning requires students to think through their presentational style, modeling is neither derivative nor normative. Modeling does not create limits or set boundaries to a students' scholarly reach, but rather expands and enlarges their awareness. As the students create their own guide and outline from their scrutiny of model articles, they deliberate on and choose what to follow and what not to. As a structure is not arbitrarily imposed on them, the S.A.M. assignments have many benefits. To begin with, students get to realize what Broekhoff (2008) pointed out so eloquently: "no academic writing, quantitative or qualitative, or indeed any kind of writing, can exist in a vacuum" (130). Since "current rhetorical and pedagogical theory posits that all academic writing is in some sense collaborative, involving a process of shared inquiry"(ibid.), the S.A.M. assignments make the students probe into that process of sharing and collaboration. Since students are asked to improve what they found, they are pushed towards bettering what they perceived or picked as the best sample available — oftentimes the authors of the articles are their supervisors or well-known scholars in their field-they develop a critical bent of mind and enter creatively into what is essentially a scholarly conversation with the writers of their model papers. The S.A.M assignments not only make new scholarly writers scrutinize the argumentative thought process of the authors of their model articles, but they also help them develop the confidence to eke out original pathways in their research and come up with their own unique paper structures and arguments.

Students move on to detailed "Macro outlining with micro details" after the S.A.M. assignments. Students may or may not adhere to the broad framework of the I.M.R.A.D or Introduction-Methods-Results-Analysis-Discussion template that scientific writing follows for instance. Students use the knowledge they gained from their examination of the two scholarly articles as well as their learning from the W.R.E. (writing and revision exercises) to guide them during the outline period. The W.R.E. are mini-lessons and offer drafting and reviewing exercises relating to Abstract, Research question, Thesis/hypothesis, Literature Review/ Theory and Objective/Overview, Methodology/ Research design, Analysis, Results/ Findings, Discussion/Significance to Inferences/ Conclusions. For instance, I coach them to write introductions as inverted pyramids, paragraphs in sandwich cookie style with distinct topic and ending sentences and research substantiation in between, and conclusion that are three-layered through WRE mini-lessons and exercises.

The outlining itself is a four leveled assignment. S.A.M.1 aids the student in creating "Macro outlining with micro details - Level 1" which is the sectional outline as well as "Macro outlining with micro details -Level 2" where writers name what the subsections under their main sections are. With S.A.M.2 guiding them, students create "Macro outlining with micro details - Level 3" that identify topic headings under the subsections as well as "Macro outlining with micro details-Level 4 outline" where topic sentences for actual paragraphs are planned. At the end of the outlining cycle, I hold the first one-on-one mid-term conference so the students can get ready to flesh out their outlines thereafter. The second one-on-one conference is held when students have written out their pre-final drafts. Since students get the best benefit from instructor inputs, feedback, and guidance at these two milestone points of the course, the conferences are scheduled at mid-term and two weeks before course closing.

\section{The Feedback Triangle}

Post mid-term conference, the course becomes even more writing intensive. As students write out their drafts in sections and get feedback from their peers online, they are also looking for content specific feedback from their dissertation supervisors. Together with the students' peers and supervisor, I, as the writing instructor, form the third vertex of the students' feedback triangle. Not only do I offer student inputs in writing but also in person at the conferences. If my goal in the first conference that is held around mid-term is to ensure that the detailed plan I am reviewing with the student leads to clear writing; I am identifying areas where revision is necessary together with my student during the second conference that is held a couple of weeks before course ends when the papers are nearly ready for submission. While both my conference and written feedback focus on students' issues with bridging into academic writing, I must point out that E.L.L (English language learners) students need extra help and feedback. Given the increasing diversity of student researchers, it is always safe for Writing for Publication teachers to make no assumptions of what the student knows. Instructors would do well to plan to spend extra time to offer beneficial sources and language help to such learners in addition to apportioning enough time for scrutinizing each student's model articles, target journal specifications, and disciplinary presentation styles that may be very different from that of the writing teacher's. Since it helps students develop an awareness of their writing process, it may also be a good idea to both begin and end the class with thoughtful exercises such as the Writing Self-assessment and end-of-thecourse Reflection respectively. As the Writing Self-assessment asks students to do a SWOT analysis on their writing skills, it 
prepares them to set objectives and get the best out of the class. Similarly the last day reflection assignment encourages students to consolidate their learning from the class and think about their writing plan for the future. As it may be helpful for fellow instructors in planning such a course, I share and explain the syllabus that I used for teaching at Rutgers University in Fall 2018 in the next section.

\section{Syllabus, Assignments, and Calendar}

$$
\begin{aligned}
& \text { Writing for Publications, Rutgers University } \\
& \text { Mode: Hybrid } \quad \text { Semester: Fall } 2018
\end{aligned}
$$

\subsection{Course Description}

Writing for Publications is aimed at graduate students preparing a document for publication. The course offers hands-on training in scientific and scholarly writing for advanced researchers. This course focuses on learning to write and edit at the level appropriate to a journal article in the student's discipline. As this course uses the workshop approach, it requires students to be invested in the work of their class colleagues. Participants do their writing assignments and critique their own work as well as the work of fellow colleagues both in and outside class. Two one-on-one conferences with the instructor are offered to discuss publishing project progress.

Close examination of scholarly articles in the student's field is undertaken as it promotes improvement in skills necessary for successful graduate work. As support for the goals of the course, students are asked to bring in current work they may be writing in their graduate courses or revise past work to explore the critical role revision plays in the writing process.

\subsection{Course Objectives}

This course enables students to learn how:

$\checkmark \quad$ To understand journal publishing processes and adapt writing to the purpose and audience that the journal caters to

$\checkmark$ To plan the scholarly article [global macro-organization; local micro- organization]; identify the content of the different sections and the main point or points; structure arguments; use evidence; write cohesive discussions and persuasive conclusions

$\checkmark$ Apply writing dimensions [purpose; audience and tone; global organization; local organization; clarity and fluency] to construct clear and coherent paragraphs and effective transitions between sentences and paragraphs of the scholarly article

$\checkmark \quad$ To develop interdisciplinary competency and be able to communicate the significance of one's work to readers who are not specialists in the area

$\checkmark$ To understand the rules defining acceptable and unacceptable citations and know how to avoid plagiarism"

$\checkmark$ To evolve as readers and reviewers through providing feedback for other writers in reader response essays through participation in online peer review workshops

$\checkmark$ To enhance the ability of participants to understand, respond and revise according to the reader reports their peers offer them.

\subsection{Course Assignments}

\section{Writing Self-assessment}

The writing self-assessment exercise is intended at helping you understand your writing process. Review comments for improvements and revisions made by your professors over the past year with the purpose of finding your strengths and areas for improvement. State your objectives and complete the form in its entirety. Remember, there is no right or wrong answer.

Pitching the proposal

Name the publication you are targeting and justify why it is your target journal in a note to me. Look inside it for a call for proposals (CFP) and study its submission guidelines. Write a formal letter to the journal describe how your article fits into the journal's area of specialization and/or call for papers. Explain why the readers of the journal will find value in your article.

Scholarly Article Modelling (SAM)-1

The purpose of SAM-1 is to analyze the macro elements of a model article from your target journal. You will design and use SAM-1 as a resource document and study guide; it will combine your observations on the organization as well as your notes on the language used in the model article. Study the macro-plan and sectional organization of the article as well as compile examples of sentences or academic phrases with the objective of coming up with your own scholarly writing technique. All directions and details may be found in the assignment instructions. 


\begin{abstract}
Scholarly Article (SAM)-2
The purpose of SAM-2 is to help you come up with strategies for the sectional paragraphs you are going to write by analyzing the microstructure of those sectional paragraphs in your second model article. Take notes on the logic and method the author used to present information within it and discuss how your techniques will be the same or different.

Macro outlining with Micro Details

You have completed your research and believe it is publication worthy. You have identified a journal and pitched your proposal to them carefully explaining why your paper is a good fit for an upcoming issue. You studied a model article and came up with an outline based on your analysis of it. Now it is time to plan how you will present your research in a paper that is organized in the structure and format that is acceptable to the journal. You will arrive at the final version of your outline in four steps. In Macro outlining with Micro Details outline 1 and 2, you will plan the various sections \& subsections of your article, while in Levels 3 and 4 , you will outline the paragraph plan for each section. All details may be found in the instructions document.
\end{abstract}

The Publishing Project

This is the writing project that you work on throughout this course. You will create paragraphs from your Level 4 outline that is in keeping with the SAM-1 and SAM-2 that emerged from your study of the model article/s. All sections of the publishable paper will be drafted as per the modeling guide and outline you evolved. Whatever your discipline, make sure you have an abstract, list of keywords and brief bio to begin with. Also ensure that you state your thesis/ hypothesis, research design, objective of study, methodology and theoretical framework at the beginning of your scholarly article. The introductory section of your paper will also feature a literature review and article overview. The body of your paper will contain the details of your study and an analysis and discussion of the findings. The concluding section of the paper will highlight the results and the inferences of your study and acknowledge any help received or known limitations. You will offer a wrap up while indicating the way forward. A list of references or work cited using the citation format that your discipline follows is required.

\title{
Reflection
}

When you finish a class, it is a good idea to take stock of what you have learned and make plans about how you will use that knowledge in the future. For a final assessment of your work in the class, you will present a Reflection PowerPoint where you will offer your thoughts about 1 ) whether the interdisciplinary nature of the class and the reader responses provided by your peers from other disciplines made you grow as a writer 2) whether the new knowledge you gained about how disciplinary expectations were similar and different benefited you as a scholar 3) how the knowledge you gained from studying target journal requirements as well as being conscious of the audience impacted your thinking and writing and 4) what you learned about writing from each assignment and exercise in the class. In closing, you could share 5) your future writing plans while critically recapitulating the distance you have covered as a writer. You will present your five-minutes long Reflections to the class on the last day, the day I return your graded projects.

Peer reviews, Self-Reviews, Class \& Conference Participation

Peer and self-reviews are central to the publishing process. You need to be able to give and accept constructive feedback and suggestions. Hence, we will be going through online peer workshops where you will use peer forms and write 3: 3: 3 SWS reader response notes WRE are writing and reviewing exercise that you will complete in order to gain awareness and find strategies on how to draft the various sections of the paper including intro \& conclusion

Participation in the two one-on-one conferences with the instructor gives you a chance to know where you stand in the class, obtain clarification on feedback and get help, inputs, and suggestions for your detailed outline and pre-final publishing project respectively.

You will also be discussing the readings in the syllabus in small and large groups. Regular attendance and participation in all activities are necessary for your success in this class. 


\subsection{Course Readings}

\subsubsection{Book Chapters}

Soule, D.P. (2007). Introducing Writing for Scholarly Journals. In D. P. Soule, et al, Eds. Writing for Scholarly Journals: Publishing in the Arts, Humanities and Social Sciences (pp. 6-10). Glasgow: e-sharp.

Corbett, J. (2007). Writing the Introduction and Conclusion of a Scholarly Article. In D. P. Soule, et al, Eds. Writing for Scholarly Journals: Publishing in the Arts, Humanities and Social Sciences (pp. 4-34 ). Glasgow: e-sharp.

Morton, C. (2007). Submission to Print: Submitting a Paper for Publication and the Publication Process. In D. P. Soule, et al, Eds. Writing for Scholarly Journals: Publishing in the Arts, Humanities and Social Sciences (pp. 34-43). Glasgow: e-sharp.

\subsubsection{Journal Articles}

Estrin, H. (1981). How to write for scientific and technical journals. Journal of Business Communication, 18.3, 55-58. Jaeger, R. G., \& Toft, C. A. (1998). Writing for scientific journals II: the review process. Herpetologica, S54-S63.

Toft, C. A., \& Jaeger, R. G. (1998). Writing for scientific journals: the manuscript. Herpetologica, S42-S54.

\subsection{Course Calendar}

\begin{tabular}{|c|c|c|}
\hline \multicolumn{3}{|c|}{ Writing For Publications: Class Plan } \\
\hline Week \# & Classwork & Homework \& Online \\
\hline Week 1 & $\begin{array}{l}\text { *Welcome, Course introduction, Goals \& } \\
\text { expectations } \\
\text { * How to do "Macro outline with micro } \\
\text { details"-Levels } 1 \text { \& } 2 \\
\text { *Understanding and planning the Publishing } \\
\text { project" } \\
\text { *“Writing Self-assessment:" Knowing your } \\
\text { strengths \& weaknesses } \\
\text { *About Target journal, CFPs, and samples } \\
\text { articles }\end{array}$ & $\begin{array}{l}\text { *Submit "Writing Self-assessment" in } \\
\text { assignment area before Week } 2 \text { class } \\
\text { *Go through assigned reading } \\
\text { *Find CFP in target journal } \\
\text { *Find a model article in the target } \\
\text { journal and take notes } \\
\text { *Find Instructions for Authors in target } \\
\text { journal and take notes }\end{array}$ \\
\hline Week 2 & $\begin{array}{l}\text { *Reading scholarly articles for content \& } \\
\text { style: Introducing "Scholarly Article } \\
\text { Modeling"-1 (SAM-1) Assignment } \\
\text { *Journal writing process: From proposal to } \\
\text { paper- Discussion with Presentation } \\
\text { *Writing and reviewing exercises (WRE): } \\
\text { "Titles" } \\
\text { *Reviewing Reading } 1 \text { (group work) }\end{array}$ & $\begin{array}{l}\text { *Go through assigned reading } \\
\text { *"Pitching your proposal:" Describe } \\
\text { how your article fits CFP and provide } \\
\text { base plan or Level } 1 \text { outline. } \\
\text { *Complete SAM-1 assignment and } \\
\text { submit before Class } 3 \\
\text { *Create Level } 2 \text { outline } \\
\text { *Start working on "Pitching the } \\
\text { proposal assignment" }\end{array}$ \\
\hline $\begin{array}{l}\text { Week } 3 \text { Online } \\
\text { PR Workshop }\end{array}$ & $\begin{array}{l}\text { *Online peer review workshop for "Pitching } \\
\text { the Proposal": Submit SWS reader } \\
\text { responses to peer review partners }\end{array}$ & $\begin{array}{l}\text { *Revise proposal after peer review for } \\
\text { conference Edit and submit "Pitching } \\
\text { the proposal" in assignment area before } \\
\text { Week } 4 \text { class }\end{array}$ \\
\hline Week 4 & $\begin{array}{l}\text { *How To Do "Macro outline with micro } \\
\text { details": Levels } 3 \text { \& } 4 \\
\text { *Structure of a scholarly paper: Discussion } \\
\text { *WRE: "Paragraph structure: Sandwich } \\
\text { Cookies \& Cones" } \\
\text { *Reviewing Reading } 2 \text { (group work) }\end{array}$ & $\begin{array}{l}\text { *Go through assigned reading } \\
\text { *Add micro-level details to macro- } \\
\text { plan: Level } 3 \text { outline }\end{array}$ \\
\hline Week 5 & $\begin{array}{l}\text { *Reviewing Reading } 3 \text { (group work) } \\
\text { *WRE: :Introduction: Research question/ } \\
\text { thesis/hypothesis" } \\
\text { *WRE exercises: "Literature Review/ Theory } \\
\text { and Objective/Overview" }\end{array}$ & $\begin{array}{l}\text { *Go through assigned reading } \\
\text { *Prepare Level } 4 \text { Global (Macro) with } \\
\text { Local (micro) plan } \\
\text { *Begin writing introductory } \\
\text { paragraphs. }\end{array}$ \\
\hline Week 6 & $\begin{array}{l}\text { *Reviewing Reading } 4 \text { (group work) } \\
\text { *Reading scholarly articles for content \& style: } \\
\text { Features of Scholarly articles, Scholarly } \\
\text { Article" Modelling- } 2 \text { or "SAM-2" } \\
\text { *WRE: "Methodology/ Research design" }\end{array}$ & $\begin{array}{l}\text { *Submit SAM-2 before next class } \\
\text { *Work on the research design and } \\
\text { methodology section of your } \\
\text { publication project (PP) } \\
\text { *Complete Level } 4 \text { plan and } \\
\text { introductory paragraphs for peer } \\
\text { review }\end{array}$ \\
\hline Week 7 Online & *Online peer review workshop of Macro & *Revise plan with opening paragraphs \\
\hline
\end{tabular}




\begin{tabular}{|c|c|c|}
\hline PR Workshop & $\begin{array}{l}\text { outlining with micro details - Level } 4 \text { plan } \\
\text { with opening paragraphs. Submit SWS } \\
\text { reader responses to peer review partners }\end{array}$ & after peer review for conference \\
\hline Week 7 & CONFERENCE \# 1 with instructor & $\begin{array}{l}\text { * Revise or complete work on Part } 1 \text { of } \\
\text { your essay containing your } \\
\text { introduction \& background sections, } \\
\text { thesis, and literature review \& theory } \\
\text { sections based on peer \& instructor } \\
\text { feedback. } \\
\text { *Take an appointment with supervisor } \\
\text { to discuss plan and introduction }\end{array}$ \\
\hline Week 8 & $\begin{array}{l}\text { *Discussion: Visual representations } \\
\text { * WRE: "Analysis" }\end{array}$ & $\begin{array}{l}* \text { Create visual /s and submit with part } \\
2 \text { of your writing project } \\
* \text { Work on the analysis sections of PP }\end{array}$ \\
\hline Week 9 & $\begin{array}{l}\text { *Discussion: How to approach revision } \\
\text { *Review of Writing process \& Reflection } \\
\text { Assignment } \\
\text { * WRE: Results/ Findings and } \\
\text { Discussion/Significance } \\
\text { *WRE: Inferences/Conclusion/Way Forward }\end{array}$ & $\begin{array}{l}\text { *Work on Part } 3 \text { of your paper namely } \\
\text { results/ findings and } \\
\text { discussion/significance/conclusion } \\
\text { paragraphs. } \\
\text { *If paper is not complete, offer } \\
\text { expanded plan for incomplete sections }\end{array}$ \\
\hline $\begin{array}{l}\text { Week } 10 \text { Online } \\
\text { PR Workshop }\end{array}$ & $\begin{array}{l}\text { *Level } 1 \text { (content)-online peer workshop of } \\
\text { draft PP, Submit SWS reader responses to } \\
\text { peer review partners }\end{array}$ & $\begin{array}{l}* \text { Revise draft PP based on feedback } \\
* \text { Complete unfinished sections }\end{array}$ \\
\hline $\begin{array}{l}\text { Week } 11 \text { Online } \\
\text { PR Workshop }\end{array}$ & $\begin{array}{l}\text { *Level } 2 \text { (mechanics)-online peer review } \\
\text { workshop, Submit } S W S \text { reader responses to } \\
\text { peer review partners }\end{array}$ & $\begin{array}{l}\text { * Revise PP second draft after peer } \\
\text { review. }\end{array}$ \\
\hline Week 12 & *Thanksgiving break, No class & $\begin{array}{l}\text { *Prepare pre-final project for } \\
\text { conference }\end{array}$ \\
\hline $\begin{array}{l}\text { Week } 13 \\
\text { Conference }\end{array}$ & *CONFERENCE \# 2 with instructor & $\begin{array}{l}\text { * Revise paper according to instructor } \\
\text { feedback. } \\
\text { *Discuss with supervisor. Revise and } \\
\text { submit for peer review using checklist }\end{array}$ \\
\hline $\begin{array}{l}\text { Week } 13 \text { Online } \\
\text { PR Workshop }\end{array}$ & $\begin{array}{l}\text { *Peer \& Self review using checklist . Submit } \\
\text { SWS reader responses to peer review } \\
\text { partners }\end{array}$ & $\begin{array}{l}\text { *Submit in assignment area as PP_Final } \\
\text { on Sunday of Week } 13 \\
\text { Ready your "Reflection" presentation }\end{array}$ \\
\hline Week 15 & $\begin{array}{l}\text { *Publication projects returned } \\
\text { *Reflection Presentations } \\
* \text { Class evaluations }\end{array}$ & $\begin{array}{l}\text { *Revise article based on final } \\
\text { instructor feedback and submit to } \\
\text { advisor } \\
\text { * Send to journal after advisor approves } \\
\text { final draft }\end{array}$ \\
\hline
\end{tabular}

\section{The Way Forward}

While the Writing for Publications syllabus and pedagogy, like all syllabi and pedagogy, will continue to evolve, what is important in the larger context is that a conversation and a consensus is necessary in the discipline about the way forward for such classes. Whether writing teachers, rather than discipline specific practitioners, should teach Writing for Publications courses may continue to be debated. What is undeniable, however, is that there is a need in young researchers for guidance in publishing and finding their niches in the academic world, making it necessary to share best practices for such Writing for Publications courses across research universities globally.

\section{References}

Ackerman, D. B., \& Perkins, D. N. (1989). Integrating Thinking and Learning Skills across the Curriculum. In Jacobs, H. (Ed.) Interdisciplinary Curriculum: Design and Implementation (pp. 77-95). Alexandria, VA: Association for Curriculum and Development.

Breuch, L. (2004). Virtual Peer Review: Teaching and Learning about Writing in Online Environments. New York: State University of New York Press.

Broekhoff, M. (2008). Templates for Academic Writing. Nawa: Journal of Language \& Communication, 2 (2), $129-139$.

Corbett, J. (2007). Writing the Introduction and Conclusion of a Scholarly Article. In D. P. Soule, et al, Eds. Writing for Scholarly Journals: Publishing in the Arts, Humanities and Social Sciences (pp. 4-34). Glasgow: e-sharp. 
Estrin, H. (1981). How to Write for Scientific and Technical Journals. Journal of Business Communication, 18 (3), 55-58.

Fox, J. A., Baloy, N., \& Sens, A. (2014). Mix and Match: Promoting Interdisciplinary Teaching, Learning, and Community through Classroom-Level Partnerships in Collected Essays on Learning and Teaching, 7 (2), 142-158.

Huang, J. C. (2017). What do Subject Experts Teach about Writing Research Articles?: An Exploratory Study. Journal of English for Academic Purposes, 25, 18-29.

Ivanitskaya, L., Clark, D., Montgomery, G. and Primeau, R. (2002). Interdisciplinary Learning: Process and Outcomes. Innovative Higher Education, 2 (2), 95-111.

Jaeger, R. G., \& Toft, C. A. (1998). Writing for Scientific Journals II: the Review Process. Herpetologica, S54-S63.

Jassawalla, A. R. \& Sashittal, H.C. (2017). What Students Think and Do in Classroom Teams When Peer Evaluations Are Highly Consequential: A Two-Stage Study. Decision Sciences Journal of Innovative Education, 15 (2), $219-247$.

Jensen, E. B. (2016). Peer-Review Writing Workshops in College Courses: Students' Perspectives about Online and Classroom based Workshops. Social Sciences, 5 (4), 72- 89.

Kaspar, W. A. (2017). The Signaling Value of Peer Review. College \& Research Libraries, 78 (5), 564-566. Liu, J., Pysarchik, D. \& Taylor, W. (2002). Peer Review in the Classroom. AIBS Bulletin, 52 (9), 824-829.

Middlebrook, R. H. (2013). Degree of Hybridity: Peer Review in the Blended Composition Classroom. Journal of Educational Technology, 10 (1), 1-9.

Morton, C. (2007). Submission to Print: Submitting a Paper for Publication and the Publication Process. In D. P. Soule, et al, Eds. Writing for Scholarly Journals: Publishing in the Arts, Humanities and Social Science (pp. 34-43). Glasgow: esharp.

Nava-Whitehead, S. M., Augusto, K.W. \& Gow, J.B. (2011). Bewitching Ideas Influence Learning: An Evaluation of an Interdisciplinary Teaching Experience. Journal of College Science Teaching, 40 (6), 359-67.

Papadopoulos, P. M., Lagkas, T.D., Stavros, N. \& Demetriadis, S.N. (2017). Technology-Enhanced Peer Review: Benefits and Implications of Providing Multiple Reviews. Journal of Educational Technology \& Society, 20 (3), 69-81.

Pritchard, R. J. \& Morrow, D. (2017). Comparison of Online and Face-To-Face Peer Review of Writing. Computers and Composition, 46, $1-46$.

Soule, D.P. (2007). Introducing Writing for Scholarly Journals, In D. P. Soule, et al, Eds. Writing for Scholarly Journals: Publishing in the Arts, Humanities and Social Sciences (pp. 6-10). Glasgow: e-sharp.

Toft, C. A., \& Jaeger, R. G. (1998). Writing for Scientific Journals: the Manuscript. Herpetologica, S42-S54.

Woods, C. (2007). Researching and Developing Interdisciplinary Teaching: Towards a Conceptual Framework for Classroom Communication. Higher Education, 54 (6), 853-866. 